\title{
The evolution of proton beam therapy: Current and future status (Review)
}

\author{
XIUFANG TIAN, KUN LIU, YONG HOU, JIAN CHENG and JIANDONG ZHANG \\ Department of Radiation Oncology, Qianfoshan Hospital Affiliated to \\ Shandong University, Jinan, Shandong 250014, P.R. China
}

Received September 7, 2017; Accepted November 9, 2017

DOI: $10.3892 / \mathrm{mco} .2017 .1499$

\begin{abstract}
Proton beam therapy (PBT) has been increasingly used in a variety of cancers due to its excellent physical properties and superior dosimetric parameters. PBT may improve patient survival by improving the local tumor treatment rate while reducing injury to normal organs, which may result in fewer radiation-induced adverse effects. However, the significant cost of establishing and maintaining proton facilities cannot be overlooked. In addition, there has been significant controversy regarding routine application of this treatment in certain types of cancer. The challenges of PBT in the future mainly include the lack of basic clinical trials, unclear biological effects, immature imaging technology and miniaturization of imaging guidance. Overcoming these limitations may promote the rapid development of PBT. We herein provide an overview of the existing literature on the efficacy and toxicity of common oncological applications of proton beam therapy.
\end{abstract}

\section{Contents}

1. Introduction

2. Physical aspects of PBT

3. Biological aspects of PBT

4. PBT for different cancers

5. Discussion

6. Conclusion

\section{Introduction}

Proton beam therapy (PBT) is a type of radiation therapy (RT). The appropriate application of PBT has led to fewer

Correspondence to: Dr Yong Hou or Dr Jiandong Zhang, Department of Radiation Oncology, Qianfoshan Hospital Affiliated to Shandong University, 66 Jingshi Road, Jinan, Shandong 250014, P.R. China

E-mail: sunnyboybaby@163.com

E-mail: zhangjd165@sina.com

Key words: proton beam therapy, tumor, dosimetric parameters, tumor control and survival, biological effects adverse effects and higher therapeutic efficacy compared with conventional RT using X-ray beams. Thus, facilities for PBT are being built worldwide, despite the requirement for costly equipment.

PBT was first proposed by Wilson (1) in 1946. After 12 years, the first PBT patient series was published (2) by researchers at the Lawrence-Berkeley National Laboratory. Over the next decades, several other proton treatment centers emerged worldwide and, thus far, PBT has used in the clinical setting for $\sim 60$ years, and has been applied to tens of thousands of patients with different types of cancer. PBT patient statistics by the end of 2015 are presented in Table I.

Over the past decades, with an increasing number of PBT applications worldwide, the number of new programs under development is growing. The reason for this is that the proton dose distribution that may be achieved is generally superior to the dose distribution of conventional photon RT. PBT may improve the survival rate of patients by improving the local tumor treatment rate, while reducing injury to normal organs, resulting in fewer radiation-induced adverse effects. Compared with conventional photon RT, the heavier subatomic particles are able to deliver their energy more precisely to the tumor, with less scattering to surrounding tissues. The clinical benefits of PBT have been acknowledged in terms of fewer side effects compared with photon therapy. However, the role of PBT remains controversial, due to the high treatment costs associated with the cost of proton facility building and maintenance. This increased cost, however, may be outweighed by effectiveness, compared with photon therapy, improved quality of life, and reduced costs associated with treatment of advanced disease. Further clinical research is required to determine which patients will benefit from PBT.

Further studies and discussions are required to address the use of PBT in several types of cancer, and for maintaining the quality of life of patients while achieving a high cure rate. The aim of this review was to report the characteristics and current developments in PBT (Table I).

\section{Physical aspects of PBT}

Protons are heavy charged particles, $\sim 800$ times the mass of electrons. The large mass and acceleration applied gives each proton a specific momentum that is mostly dissipated after traveling a defined distance, and then slowed down 
by interactions with the target, which causes a sharp rise in energy deposition at the end of the path of the proton, followed by no further dose delivery, which is referred to as the Bragg peak (3). This individual physical property provides superior dosimetric advantages over photons or electrons. Therefore, rather than traversing the target, protons are stopped at an energy-dependent depth in the target and have no exit dose, which completely spares the downstream normal tissue. Proton beams are generated by a cyclotron or synchrotron, and then accelerated to the desired target. Fig. 1 depicts the percentage depth-dose distribution curves of the proton vs. the photon beam, demonstrating that, at the prescribed depth, the proton beam does not deliver a dose, whereas the photon beam does.

\section{Biological aspects of PBT}

In RT, the proton dose is presented as Gy, which is determined from multiplying the physical dose by the relative biological effectiveness (RBE). Therefore, the clinical and biological effect may differ when the physical dose remains constant and the radiation quality changes. The RBE is used to link the biological effect to a reference radiation $\left({ }^{60} \mathrm{Co}\right)$. For external beam RT, which uses photons and electrons, the RBE is generally to be considered $1(4,5)$.

Protons have completely different dose distribution properties compared with photons, and have the potential to avoid most of the extra-target radiation, imparted by the acceleration system that gives protons a specific momentum that carries them into a body. After traveling a specified distance, the velocity is slowed by interactions associated with their mass and charge, and then stopped abruptly at a specific depth. This is the point at which the proton will interact with surrounding electrons, delivering its energy and causing ionization of molecules and radiation damage in the DNA of the target cell.

Protons are characterized by low linear energy transfer radiation, and tissue damage is caused by single-strand DNA breaks, with sublethal radiation damage and potential radiation damage repair. The biological effect depends on the dose per treatment, which is slightly higher compared with that of ${ }^{60} \mathrm{Co}$ and high-energy X-rays. The RBE of the proton beam is generally considered to be 1.1 (6). However, near the end of the proton range, the stopping power increases, resulting in an increase in $\mathrm{RBE}$. If a uniform $\mathrm{RBE}$ of 1.1 is used in proton planning, the varying RBE at the end of the range is not clearly accounted for. Due to these uncertainties, proton beam angles with critical organs at risk directly distal to the tumor are generally not used, and multiple beams are used to spread out the end of range uncertainty. With pencil beam scanning, the interaction of dynamic delivery with a moving target must be evaluated and minimized. Overall, at the biological level, there remain several uncertainties in our understanding of the interaction between protons and human tissues.

\section{PBT for different cancers}

Head and neck tumors. Previous studies (7-10) suggested that patients with head and neck cancer may benefit from PBT. PBT may decrease the recurrence risk by increasing the dose to the tumor and, due to the small dose to the mandible, salivary glands and maxilla, it may reduce the risk of xerostomia, dental extractions, dental caries and osteoradionecrosis.

For sinonasal mucosal malignant melanoma, there is evidence that hypofractionated high-dose PBT may improve the local control rate. Compared with surgery in patients with sinonasal mucosal malignant melanoma, the continuous control of the primary lesions may achieve a higher survival rate (11).

Considering intraocular melanoma, currently available data indicate that surgical removal is the optimal approach; however, sensitivity analyses indicated that both PBT and plaque brachytherapy may be considered effective (12). Compared with radioactive plaques, PBT has a number of advantages, including that surgery is not required, medical workers are not exposed to radiation and there is no need for hospital stay, while treatment is performed in 5 working days. Due to these advantages, an increasing number of patients opt for PBT rather than radioactive plaques.

PBT for uveal melanoma and other malignant and benign ocular tumors has been associated with major developments and success over the past four decades. PBT is associated with the lowest overall risk of local tumor recurrence in uveal melanoma, compared with other eye-preserving forms of primary treatment. PBT is also utilized for other malignant and benign tumors as primary, salvage, or adjuvant treatment with combined modality therapy. The physical characteristics of proton therapy allows for uniform dose distribution, minimal scatter, and sharp dose fall-off, making it an ideal therapy for ocular tumors in which critical structures lay in close proximity to the tumor. High radiation doses can be delivered to tumors with relative sparing of adjacent tissues from collateral damage. PBT for ocular tumors has resulted in overall excellent chances for tumor control, ocular conservation, and visual preservation. The treatment of uveal melanomas and other ocular tumors has been extensively evaluated for decades and PBT is considered the gold standard of care.

When considering skull base chordoma, previous results demonstrated that, by producing a greater probability of long-term tumor control, PBT is more effective compared with $\mathrm{X}$-ray therapy, while causing no increasing risk of temporal lobe injury. A number of tumors encompassing regions of the skull base have demonstrated a proven benefit from PBT based on retrospective results. Studies into dose escalation and conformal treatment plans with PBT may further improve outcomes in these disease sites, without an increased risk of toxicity to normal structures (13).

PBT is also considered a standard treatment for nasal and paranasal lesions, as well as lesions at the base of the skull, as the radiation dose to critical organs, such as the eyes, optic nerves and central nervous system, may be reduced with PBT (14).

Chest tumors. Lung cancer is the most common type of cancer worldwide and RT is an important treatment mode. PBT is a type of RT that has the potential to reduce the toxicity of RT through its characteristic Bragg peak. In comparison with photons, PBT plans may deliver lower doses to the adjacent organs at risk, such as the esophagus, lungs and bone marrow, thus improving the therapeutic ratio (15). The early clinical 
Table I. Proton beam therapy patient statistics until the end of 2015 (data collected by the Particle Therapy Cooperative Group).

\begin{tabular}{|c|c|c|c|c|}
\hline Country, state & Site & Year of first treatment & Patient total & Date of last update \\
\hline Belgium & Louvain-la-Neuve & 1991 & 21 & 1993 \\
\hline Canada & Vancouver (TRIUMF) & 1995 & 185 & 2015.12 \\
\hline Czech Republic & Prague (PTCCZ) & 2012 & 780 & 2015.12 \\
\hline China & Wanjie (WPTC) & 2004 & 1,078 & 2015.12 \\
\hline China & Shanghai (SPHIC) & 2014 & 76 & 2015.12 \\
\hline England & Clatterbridge & 1989 & 2,813 & 2015.12 \\
\hline France & Nice (CAL) & 1991 & 5,478 & 2015.12 \\
\hline France & Orsay (CPO) & 1991 & 7,560 & 2015.12 \\
\hline Germany & Berlin (HMI) & 1998 & 2,750 & 2015.12 \\
\hline Germany & Munich (RPTC) & 2009 & 2,725 & 2015.12 \\
\hline Germany & Heidelberg (HIT) & 2009 & 1,187 & 2015.12 \\
\hline Germany & Essen (WPE) & 2013 & 366 & 2015.12 \\
\hline Germany & Dresden (UPTD) & 2014 & 106 & 2015.12 \\
\hline Italy & Catania (INFN-LNS) & 2002 & 350 & 2015.12 \\
\hline Italy & Pavia (CNAO) & 2011 & 195 & 2015.12 \\
\hline Italy & Trento (APSS) & 2014 & 92 & 2015.12 \\
\hline Japan & Chiba & 1979 & 145 & 2002 \\
\hline Japan & Tsukuba (PMRC, 1) & 1983 & 700 & 2000 \\
\hline Japan & Chiba (HIMAC) & 1994 & 138 & 2015.12 \\
\hline Japan & Kashiwa (NCC) & 1998 & 1,560 & 2015.12 \\
\hline Japan & Hyogo (HIBMC) & 2001 & 5,024 & 2015.12 \\
\hline Japan & Tsuruga (WERC) & 2002 & 62 & 2009 \\
\hline Japan & Tsukuba (PMRC, 2) & 2001 & 4,502 & 2015.12 \\
\hline Japan & Shizuoka (PTCC) & 2003 & 1,873 & 2015.12 \\
\hline Japan & Koriyama (STPTC) & 2008 & 2,797 & 2014.12 \\
\hline Japan & Ibusuki (MMRI) & 2011 & 1654 & 2015.12 \\
\hline Japan & Fukui (Prefectural Hospital) & 2011 & 646 & 2015.8 \\
\hline Japan & Nagoya (Nagoya PTC) & 2013 & 1,095 & 2015.12 \\
\hline Japan & Nagano (Aizawa PTC) & 2014 & 1 & 2014.9 \\
\hline Poland & Krakow (IFJ PAN) & 2011 & 128 & 2015.12 \\
\hline Russia & Dubna (JINR, 1) & 1967 & 124 & 1996 \\
\hline Russia & Moscow (ITEP) & 1969 & 4,368 & 2015.12 \\
\hline Russia & St. Petersburg & 1975 & 1,386 & 2012.12 \\
\hline Russia & Dubna (JINR, 2) & 1999 & 1,122 & 2015.12 \\
\hline South Africa & Capetown (Themba LABS) & 1993 & 524 & 2015.12 \\
\hline South Korea & Ilsan, Seoul (KNCC) & 2007 & 1,781 & 2015.12 \\
\hline South Korea & Seoul (Samsung PTC) & 2015 & 4 & 2015.12 \\
\hline Sweden & Uppsala (1) & 1957 & 73 & 1976 \\
\hline Sweden & Uppsala (2) & 1989 & 1,431 & 2014 \\
\hline Sweden & Uppsala (The Skandion Clinic) & 2015 & 32 & 2015.12 \\
\hline Switzerland & Villigen PSI (OPTIS 1) & 1984 & 5,458 & 2010 \\
\hline Switzerland & Villigen-PSI, incl OPTIS2 & 1996 & 2,242 & 2015.12 \\
\hline USA, CA & Berkeley 184 & 1954 & 30 & 1957 \\
\hline USA, MA & Harvard (HCL) & 1961 & 9116 & 2002 \\
\hline USA, CA & Loma Linda (LLUMC) & 1990 & 18,362 & 2014.12 \\
\hline USA, IN & Bloomington (MPRI, 1) & 1993 & 34 & 1999 \\
\hline USA, CA & San Francisco (UCSF-NL) & 1994 & 1,839 & 2015.12 \\
\hline USA, MA & Boston (NPTC) & 2001 & 8,358 & 2015.12 \\
\hline USA, IN & Bloomington (IU Health PTC) & 2004 & 2,200 & 2014 \\
\hline USA, TX & Houston (MD Anderson) & 2006 & 6,631 & 2015.12 \\
\hline USA, FL & Jacksonville (UFPTI) & 2006 & 6,107 & 2015.12 \\
\hline USA, OK & Oklahoma (ProCure PTC) & 2009 & 2,079 & 2015.12 \\
\hline
\end{tabular}


Table I. Continued.

\begin{tabular}{|c|c|c|c|c|}
\hline Country, state & Site & Year of first treatment & Patient total & Date of last update \\
\hline USA, PA & Philadelphia (UPenn) & 2010 & 3,376 & 2015.12 \\
\hline USA, IL & CDH Warrenville & 2010 & 2,316 & 2015.12 \\
\hline USA, VA & Hampton (HUPTI) & 2010 & 1,399 & 2015.12 \\
\hline USA, NY & New Jersey (ProCure PTC) & 2012 & 1,862 & 2015.12 \\
\hline USA, WA & Seattle (SCCA ProCure PTC) & 2013 & 844 & 2015.12 \\
\hline USA, MO & St. Louis (S. Lee King PTC) & 2013 & 270 & 2015.12 \\
\hline USA, TN & Knowville (Provision Center) & 2014 & 856 & 2015.12 \\
\hline USA, CA & San Diego (Scripps PTC) & 2014 & 400 & 2015.12 \\
\hline USA, LA & Shreveport (Willis Knighton) & 2014 & 151 & 2015.12 \\
\hline USA, FL & Jacksonville (Ackerman CC) & 2015 & 140 & 2015.12 \\
\hline USA, MN & Rochester (Mayo PBTC) & 2015 & 186 & 2016.8 \\
\hline USA, NJ & Brunswick (Laurie PC) & 2015 & 50 & 2015.12 \\
\hline USA, TX & Irving (Texas Center for PT) & 2015 & 1 & 2015.12 \\
\hline USA, TN & Memphis (St. Jude PTC) & 2015 & 1 & 2015.12 \\
\hline Total & & 1954 & 131,240 & 2015 \\
\hline
\end{tabular}

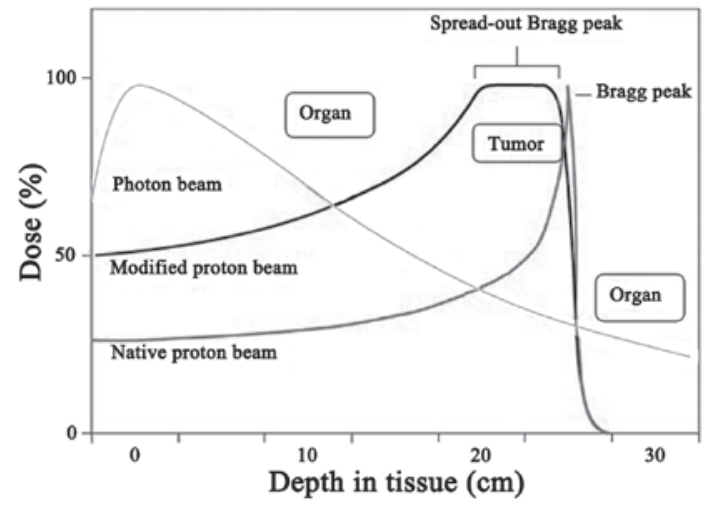

Figure 1. Percentage depth-dose distribution curves of proton beam vs. photon beam.

outcome of PBT in lung cancer patients (16-23) demonstrated that proton beam therapy combined with chemotherapy may relatively reduce the rates of toxicity and achieve a possible survival benefit compared with photon beam therapy and 3DCRT (24). Early results (25-29) suggested that PBT has the advantage of dose escalation, which may prolong patient survival, lower the risk of recurrence and severe toxicity, and intensify chemotherapy (15). For patients with stage III NSCLC, PBT may be an effective and safe treatment option. However, late toxicities remain unclear, and patients should continue to be followed up to determine these risks (30).

Foresophageal and gastroesophageal junction cancers (31-35), the esophagus is a centrally located thoracic structure; thus, there is a more stringent requirement to balance the delivery of the proper high dose to the target, while decreasing the dose to adjacent critical tissues, due to the risk of clinically significant toxicities, including pericarditis, pneumonitis and myocardial infarction. Although technological advancements in photon RT delivery, such as intensity-modulated RT (IMRT), have reduced the risk of such toxicities, accumulating evidence indicates that further risk reductions are achieved with PBT (36-40). Since
PBT has a zero exit dose, it is possible to further reduce the radiation exposure of normal tissue and provide clinically significant benefits to at least a proportion of patients with esophageal cancer. Furthermore, it may be possible to reduce cardiac-related complications and mortality by using proton beams to treat patients with esophageal cancer (41). High-dose PBT without chemotherapy was found to be efficacious and safe for the treatment of older patients with esophageal cancer (42).

In general, a growing body of evidence suggests that the dosimetric benefits of PBT may lead to a clinically significant reduction in treatment-related toxicities compared with conventional photon RT (43). RT and chemotherapy intensification, as well as re-irradiation, are promising future applications of PBT for esophageal cancer.

For breast cancer, it has been demonstrated that PBT was cost-effective, while standard photon radiation led to significant side effect in women at high risk of cardiac disease (44). Compared with conventional X-rays and electron beams, it was found that partial breast irradiation using PBT was safer, more effective and technically feasible; furthermore, it may provide satisfactory target coverage and improve normal tissue sparing. Moreover, compared with intracavitary and interstitial brachytherapy, PBT was found to be more cost-effective (45-54).

Abdominal and pelvic tumors. Although PBT has been used for several years to treat prostate cancer, this type of treatment remains controversial. Although the proton beam has unique physical properties and excellent dosimetric parameters, the currently available evidence suggests that the application of PBT in the treatment of prostate cancer offers no proven advantage over conventional IMRT. In addition, a number of the current treatment options, including brachytherapy, prostatectomy and IMRT, are more cost-effective compared with PBT. Thus, further research with adequate follow-up data is required to assess the clinical superiority of PBT in treating prostate cancer, in terms of improving the tumor control rate and reducing acute and long-term radiation toxicity. PBT is an important method of 
RT due to its theoretical advantage over photon external beam RT. However, there is little consensus regarding whether significant toxicity or outcome benefits exist, and whether the benefits outweigh the cost of adopting an expensive new technology (55). Thus, long-term follow up is required to justify the increasing use of PBT for prostate cancer.

It has been demonstrated that PBT is a safe and effective method for patients with localized prostate cancer (56-59). However, it is necessary to further compare PBT with other treatment regimens for local prostate cancer to determine the optimal treatment regimen for different patients (60). Further comparative studies that address adverse effects, safety, patient quality of life and socioeconomic issues should be performed to determine the appropriate use of PBT for prostate cancer (13).

Pediatric cancers. Although there has been significant progress in RT technology (61), there remain concerns on treatment-related acute and long-term side effects. This problem is more pronounced in pediatric populations due to the development of organs and tissues and the longer life expectancy, which include the effect of radiation on growth, intellectual development, endocrine organ function and secondary cancer development; thus, the pediatric radiation dose to normal tissues should be reduced as much as possible (62-66). PBT has the advantage of reducing the dose exposure of normal tissue, which may lead to fewer adverse effects. For this reason, PBT may be useful for the treatment of pediatric cancer (13).

Dosimetric and clinical researches have demonstrated that, in the treatment of pediatric tumors, such as medulloblastoma, retinoblastoma, bone sarcoma, pelvic soft tissue sarcoma and orbital rhabdomyosarcoma, in terms of reducing dose and injury to healthy organs, PBT has a significant advantage compared with X-ray therapy $(67,68)$. The risk of radiation-induced secondary cancer in children with cholangiocarcinoma treated with RT was also found to be the highest after X-ray therapy, and the lowest after intensive proton therapy (69). The increased risk of coronary artery disease and valvular dysfunction was found to be associated with cardiac irradiation during X-ray treatment of Hodgkin's lymphoma $(70,71)$. Therefore, in order to reduce the morbidity, mortality, pain and health care costs of Hodgkin's lymphoma survivors, PBT may be a feasible option.

As the irradiation dose to normal tissue should particularly be reduced as much as possible in children, PBT has recently attracted worldwide attention as an RT modality for pediatric cancer (72).

Other cancers. PBT has potential advantages for the treatment of rectal and anal cancers due to the lower dose to the bladder, bowel and hip joints; it may also have potential advantages for pancreatic, gastric and hepatobiliary cancers, as it delivers a lower dose to the liver, small bowel, lungs, heart, spinal cord and kidneys, and may also be used for bone and soft tissue sarcomas. PBT may allow dose intensification of chemotherapy by improved hematological tolerance in gastrointestinal, thoracic, and other types of cancer (73).

\section{Discussion}

PBT has several potential advantages over photon therapy for the treatment of cancer. The entrance dose is low, the exit dose is almost zero, and most of the beam energy is delivered to a specified depth. However, given the persistent uncertainties regarding PBT planning and delivery, the lack of evidence supporting the use of protons over photons, the higher cost of proton therapy, and limited access and expertise with proton techniques, protons continue to lag behind contemporary photons.

PBT may offer a substantial potential benefit in special cases, particularly in terms of toxicity compared with photon treatments. Due to the lower cumulative doses to the sensitive organs, re-irradiation using PBT may be safer for patients with rectal, pancreatic, esophageal and lung cancer. In addition, for patients with Hodgkin's and non-Hodgkin lymphoma, it may be suitable to use PBT for consolidation following chemotherapy. With the technological improvements in proton therapy, by maintaining the benefits of RT while further minimizing the risks, the therapeutic ratio may be increased (74).

The physical properties of protons have been extensively investigated. Further research on the development of confined proton technology should focus on clinical trials investigating its biological effects and clinical applications.

The effectiveness of proton RT has not been supported by adequate patient data, and no large number of direct clinical trials have demonstrated that proton protection of normal tissue may prolong survival in cancer patients. In addition, data on the relative biological effect on different tumor cells and normal tissue cells under proton irradiation remain scarce.

Due to the position of the tumor patients, breathing movements, and other factors that may lead to uncertainties in proton $\mathrm{RT}$, it is difficult to ensure that the beam may be delivered to the designated location with the utmost precision and, once a deviation occurs, the precise nature of the proton may become a disadvantage, inevitably leading to normal tissue irradiation whereas a part of the tumor will not be irradiated. If such problems occur, the advantages of proton RT are greatly reduced. In traditional photon RT, image-guided techniques may be used to reduce such uncertainties. However, proton RT using image guidance technology is immature, as the majority of the techniques remain at the two-dimensional stage.

\section{Conclusion}

PBT is the latest type of RT, which exerts a satisfactory curative effect, particularly in pediatric patients. In recent years, an increasing number of patients are treated with PBT worldwide. PBT can achieve a dose distribution that is generally superior to conventional external photon beam radiation. Compared with photon therapy, PBT is associated with obvious benefits, such as reducing the volume of irradiated normal tissue, improving the conformability and the quality of the target area. However, PBT is costlier compared with conventional $\mathrm{X}$-ray therapy, although this increased cost may be outweighed by improving the quality of life of the patients and reducing the costs associated with treating late radiation-related adverse effects. However, the relative biological effect of PBT requires further investigation.

Future studies must integrate, evaluate and manage information associated with PBT, in order to provide patients with the optimal treatment while reducing injury to normal tissues and treatment costs, and to clearly determine which patients may benefit the most from PBT. 


\section{References}

1. Wilson RR: Radiological use of fast protons. Radiology 47: 487-491, 1946.

2. Lawrence JH, Tobias CA, Born JL, McCombs RK, Roberts JE, Anger HO, Low-Beer BV and Huggins CB: Pituitary irradiation with high-energy proton beams: A preliminary report. Cancer Res 18: 121-134, 1958

3. Bragg WH and Kleeman R: XXXIX. On the $\alpha$ particles of radium, and their loss of range in passing through various atoms and molecules. Philos Mag 10: 318-340, 1905.

4. Jäkel O, Smith AR and Orton CG: The more important heavy charged particle radiotherapy of the future is more likely to be with heavy ions rather than protons. Med Phys 40: 090601, 2013

5. Paganetti H, Niemierko A, Ancukiewicz M, Gerweck LE, Goitein M, Loeffler JS and Suit HD: Relative biological effectiveness (RBE) values for proton beam therapy. Int J Radiat Oncol Biol Phys 53: 407-421, 2002.

6. Paganetti H, Niemierko A, Ancukiewicz M, Gerweck LE, Goitein M, Loeffler JS and Suit HD: Relative biological effectiveness (RBE) values for proton beam therapy. Int J Radiat Oncol Biol Phys 53: 407-421, 2002.

7. Van de Water TA, Lomax AJ, Bijl HP, De Jong ME, Schilstra C, Hug EB and Langendijk JA: Potential benefits of scanned intensity-modulated proton therapy versus advanced photon therapy with regard to sparing of the salivary glands in oropharyngeal cancer. Int J Radiat Oncol Biol Phys 79: 1216-1224, 2011.

8. Slater JD, Yonemoto LT, Mantik DW, Bush DA, Preston W, Grove RI, Miller DW and Slater JM: Proton radiation for treatment of cancer of the oropharynx: Early experience at Loma Linda university medical center using a concomitant boost technique. Int J Radiat Oncol Biol Phys 62: 494-500, 2005.

9. Fitzek MM, Thornton AF, Varvares M, Ancukiewicz M, Mcintyre J, Adams J, Rosenthal S, Joseph M and Amrein P: Neuroendocrine tumors of the sinonasal tract. Results of a prospective study incorporating chemotherapy, surgery, and combined proton-photon radiotherapy. Cancer 94: 2623-2634, 2002.

10. Truong MT, Kamat UR, Liebsch NJ, Curry WT, Lin DT, Barker FG II, Loeffler JS and Chan AW: Proton radiation therapy for primary sphenoid sinus malignancies: Treatment outcome and prognostic factors. Head Neck 31: 1297-1308, 2009.

11. Fuji H, Yoshikawa S, Kasami M, Murayama S, Onitsuka T, Kashiwagi $\mathrm{H}$ and Kiyohara Y: High-dose proton beam therapy for sinonasal mucosal malignant melanoma. Radiat Oncol 9: 162, 2014.

12. Moriarty JP, Borah BJ, Foote RL, Pulido JS and Shah ND: Cost-effectiveness of proton beam therapy for intraocular melanoma. PLoS One 10: e0127814, 2015.

13. Ahmed KA, Demetriou SK, McDonald M and Johnstone PA: Clinical benefits of proton beam therapy for tumors of the skull base. Cancer Control 23: 213-219, 2016

14. Sakurai H, Ishikawa $H$ and Okumura T: Proton beam therapy in Japan: Current and future status. Jpn J Clin Oncol 46: 885-892, 2016.

15. Berman AT, James SS and Rengan R: Proton beam therapy for non-small cell lung cancer: Current clinical evidence and future directions. Cancers (Basel) 7: 1178-1190, 2015.

16. Wu CT, Motegi A, Motegi K, Hotta K, Kohno R, Tachibana H, Kumagai M, Nakamura N, Hojo H, Niho S, et al: Dosimetric comparison between proton beam therapy and photon radiation therapy for locally advanced non-small cell lung cancer. Jpn J Clin Oncol: Aug 10, 2016 (Epub ahead of print).

17. Bradley JD, Bae K, Graham MV, Byhardt R, Govindan R, Fowler J, Purdy JA, Michalski JM, Gore E and Choy H: Primary analysis of the phase II component of a phase I/II dose intensification study using three-dimensional conformal radiation therapy and concurrent chemotherapy for patients with inoperable non-small-cell lung cancer: RTOG 0117. J Clin Oncol 28: 2475-2480, 2010.

18. Iwata H, Demizu Y, Fujii O, Terashima K, Mima M, Niwa Y, Hashimoto N, Akagi T, Sasaki R, Hishikawa Y, et al: Long-term outcome of proton therapy and carbon-ion therapy for large (T2a-T2bNOM0) non-small-cell lung cancer. J Thorac Oncol 8: 726-735, 2013

19. Dunlap NE, Larner JM, Read PW, Kozower BD, Lau CL, Sheng K and Jones DR: Size matters: A comparison of T1 and T2 peripheral non-small-cell lung cancers treated with stereotactic body radiation therapy (SBRT. J Thorac Cardiovasc Surg 140: 583-589, 2010.
20. Kanemoto A, Okumura T, Ishikawa H, Mizumoto $\mathrm{M}$, Oshiro Y, Kurishima K, Homma S, Hashimoto T, Ohkawa A, Numajiri $\mathrm{H}$, et al: Outcomes and prognostic factors for recurrence after high-dose proton beam therapy for centrally and peripherally located stage I non-small-cell lung cancer. Clin Lung Cancer 15: e7-e12, 2014.

21. Socinski MA, Blackstock AW, Bogart JA, Wang X, Munley M, Rosenman J, Gu L, Masters GA, Ungaro P, Sleeper A, et al: Randomized phase II trial of induction chemotherapy followed by concurrent chemotherapy and dose-escalated thoracic conformal radiotherapy (74 Gy) in stage III non-small-cell lung cancer. J Clin Oncol 26: 2457-2463, 2008.

22. Koto M, Takai Y, Ogawa Y, Matsushita H, Takeda K, Takahashi C, Britton KR, Jingu K, Takai K, Mitsuya M, et al: A phase II study on stereotactic body radiotherapy for stage I non-small cell lung cancer. Radiother Oncol 85: 429-434, 2007.

23. Rosenman JG, Halle JS, Socinski MA, Deschesne K, Moor DT, Johnson H, Fraser R and Morris DE: High-dose conformal radiotherapy for treatment of stage IIIA/IIIB non-small-cell lung cancer: Technical issues and results of a phase I/II trial. Int J Radiat Oncol Biol Phys 54: 348-356, 2002.

24. Schild SE, Rule WG, Ashman JB, Vora SA, Keole S, Anand A, Liu W and Bues M: Proton beam therapy for locally advanced lung cancer: A review. World J Clin Oncol 5: 568-575, 2014.

25. Chang JY, Komaki R, Lu C, Wen HY, Allen PK, Tsao A, Gillin M, Mohan R and Cox JD: Phase 2 study of high-dose proton therapy with concurrent chemotherapy for unresectable stage III nonsmall celllung cancer. Cancer 117: 4707-4713, 2011.

26. Cox JD: Are the results of RTOG 0617 mysterious? Int J Radiat Oncol Biol Phys 82: 1042-1044, 2012.

27. Oshiro Y, Okumura T, Kurishima K, Homma S, Mizumoto M, Ishikawa H, Onizuka M, Sakai M,Goto Y,Hizawa N, et al: High-dose concurrent chemo-proton therapy for Stage III NSCLC: Preliminary results of a Phase II study. J Radiat Res 55: 959-965, 2014.

28. Bradley JD, Paulus R, Komaki R, Masters G, Blumenschein G, SchildS,Bogart J,Hu C,ForsterK, Magliocco A, et al:Standard-dose versus high-dose conformal radiotherapy with concurrent and consolidation carboplatin plus paclitaxel with or without cetuximab for patients with stage IIIA or IIIB non-small-cell lung cancer (RTOG 0617): A randomised, two-by-two factorial phase 3 study. Lancet Oncol 16: 187-199, 2015.

29. Ohno T, Oshiro Y, Mizumoto M, Numajiri H, Ishikawa H, Okumura T, Terunuma T, Sakae T and Sakurai H: Comparison of dose-volume histograms between proton beam and X-ray conformal radiotherapy for locally advanced non-small-cell lung cancer. J Radiat Res 56: 128-133, 2015.

30. Takada A, Nakamura T, Takayama K, Makita C, Suzuki M, Azami Y, Kato T, Tsukiyama I, Hareyama M, Kikuchi Y, et al: Preliminary treatment results of proton beam therapy with chemoradiotherapy for stage I-III esophageal cancer. Cancer Med 5: 506-515, 2016.

31. Kato K, Muro K, Minashi K, Ohtsu A, Ishikura S, Boku N, Takiuchi H, Komatsu Y, Miyata Y and Fukuda H; Gastrointestinal Oncology Study Group of the Japan Clinical Oncology Group (JCOG): Phase II study of chemoradiotherapy with 5-fluorouracil and cisplatin for Stage II-III esophageal squamous cell carcinoma: JCOG trial (JCOG 9906). Int J Radiat Oncol Biol Phys 81: 684-690, 2011

32. Ishikura S, Nihei K, Ohtsu A, Boku N, Hironaka S, Mera K, Muto M, Ogino T and Yoshida S: Long-term toxicity after definitive chemoradiotherapy for squamous cell carcinoma of the thoracic esophagus. J Clin Oncol 21: 2697-2702, 2003.

33. Shirai K, Tamaki Y, Kitamoto Y, Murata K, Satoh Y, Higuchi K, Nonaka T, Ishikawa H, Katoh H, Takahashi T and Nakano T: Dose-volume histogram parameters and clinical factors associated with pleural effusion after chemoradiotherapy in esophageal cancer patients. Int J Radiat Oncol Biol Phys 80: 1002-1007, 2011

34. Morota M, Gomi K, Kozuka T, Chin K, Matsuura M, Oguchi M, Ito $\mathrm{H}$ and Yamashita $\mathrm{T}$ : Late toxicity after definitive concurrent chemoradiotherapy for thoracic esophageal carcinoma. Int J Radiat Oncol Biol Phys 75: 122-128, 2009.

35. Okonogi N, Hashimoto T, Ishida M, Ohno T, Terunuma T, Okumura T, Sakae T and Sakurai H: Designed-seamless irradiation technique for extended whole mediastinal proton-beam irradiation foresophageal cancer. Radiat Oncol 7: 173, 2012.

36. Ishikawa H, Hashimoto T, Moriwaki T, Hyodo I, Hisakura K, Terashima H, Ohkohchi N, Ohno T, Makishima H, Mizumoto $\mathrm{M}$, et al: Proton beam therapy combined with concurrent chemotherapy for esophageal cancer. Anticancer Res 35: 1757-1762, 2015. 
37. Koyama S and Tsujii H: Proton beam therapy with high-dose irradiation for superficial and advanced esophageal carcinomas. Clin Cancer Res 9: 3571-3577, 2003.

38. Mizumoto M, Sugahara S, Nakayama H, Hashii H, Nakahara A Terashima H, Okumura T, Tsuboi K, Tokuuye K and Sakurai H: Clinical results of proton-beam therapy for locoregionally advanced esophageal cancer. Strahlenther Onkol 186: 482-488, 2010.

39. Sugahara S, Tokuuye K, Okumura T, Nakahara A, Saida Y, Kagei K, Ohara K, Hata M, Igaki H and Akine Y: Clinical results of proton beam therapy for cancer of the esophagus. Int J Radiat Oncol Biol Phys 61: 76-84, 2005.

40. Makishima $H$, Ishikawa $H$, Terunuma $T$, Hashimoto $T$, Yamanashi K, Sekiguchi T, Mizumoto M, Okumura T, Sakae T and Sakurai H: Comparison of adverse effects of proton and $\mathrm{X}$-ray chemoradiotherapy for esophageal cancer using an adaptive dose-volume histogram analysis. J Radiat Res 56: 568-576, 2015.

41. Lin SH, Hallemeier CL and Chuong M: Proton beam therapy for the treatment of esophageal cancer. Chin Clin Oncol 5: 53, 2016.

42. Ono T, Nakamura T, Azami Y, Yamaguchi H, Hayashi Y, Suzuki M, Hatayama Y, Tsukiyama I, Hareyama M, Kikuchi Y and Nemoto K: Clinical results of proton beam therapy for twenty older patients with esophageal cancer. Radiol Oncol 49: 371-378, 2015.

43. Chuong MD, Hallemeier CL, Jabbour SK, Yu J, Badiyan S, Merrell KW, Mishra MV, Li H, Verma V and Lin SH: Improving outcomes for esophageal cancer using proton beam therapy. Int J Radiat Oncol Biol Phys 95: 488-497, 2016.

44. Reiazi R, Norozi A and Etedadialiabadi M: A Literature survey on cost-Effectiveness of proton beam therapy in the management of breast cancer patients. Iran J Cancer Prev 8: e4373, 2015.

45. Johansson J, Isacsson U, Lindman H, Montelius A and Glimelius B: Node-positive left-sided breast cancer patients after breast-conserving surgery: Potential outcomes of radiotherapy modalities and techniques. Radiother Oncol 65: 89-98, 2002

46. Kozak KR, Smith BL, Adams J, Kornmehl E, Katz A, Gadd M, Specht M, Hughes K, Gioioso V and Lu HM, et al: Accelerated partial-breast irradiation using proton beams: Initial clinical experience. Int J Radiat Oncol Biol Phys 66: 691-698, 2006.

47. Kozak KR, Katz A, Adams J, Crowley EM, Nyamwanda JA, Feng JK, Doppke KP, Delaney TF and Taghian AG: Dosimetric comparison of proton and photon three-dimensional, conformal, external beam accelerated partial breast irradiation techniques. Int J Radiat Oncol Biol Phys 65: 1572-1578, 2006.

48. Lomax AJ, Cella L, Weber D, Kurtz JM and Miralbell R: Potential role of intensity-modulated photons and protons in the treatment of the breast and regional nodes. Int $\mathrm{J}$ Radiat Oncol Biol Phys 55: 785-792, 2003.

49. Bush DA, Slater JD, Garberoglio C, Do S, Lum S and Slater JM: Partial breast irradiation delivered with proton beam: Results of a phase II trial. Clin Breast Cancer 11: 241-245, 2011.

50. Weber DC, Ares C, Lomax AJ and Kurtz JM: Radiation therapy planning with photons and protons for early and advanced breast cancer: An overview. Radiat Oncol 1: 22, 2006.

51. Lundkvist J, Ekman M, Ericsson SR, Isacsson U, Jönsson B and Glimelius B: Economic evaluation of proton radiation therapy in the treatment of breast cancer. Radiother Oncol 75: 179-185, 2005

52. Clarke M, Collins R, Darby S, Davies C, Elphinstone P, Evans E, Godwin J, Gray R, Hicks C, James S, et al: Effects of radiotherapy and of differences in the extent of surgery for early breast cancer on local recurrence and 15-year survival: An overview of the randomised trials. Lancet 366: 2087-2106, 2005

53. Bush DA, Slater JD, Garberoglio C, Yuh G, Hocko JM and Slater JM: A technique of partial breast irradiation utilizing proton beam radiotherapy: comparison with conformal $\mathrm{x}$-ray therapy. Cancer J 13: 114-118, 2007.

54. Taghian AG, Kozak KR, Katz A, Adams J, Lu HM, Powell SN and DeLaney TF: Accelerated partial breast irradiation using proton beams: initial dosimetric experience. Int J Radiat Oncol Biol Phys 65: 1404-1410, 2006.

55. Mahal BA, Chen YW, Efstathiou JA, Muralidhar V, Hoffman KE, Yu JB, Feng FY, Beard CJ, Martin NE, Orio PF III and Nguyen PL: National trends and determinants of proton therapy use for prostate cancer: A national cancer data base study. Cancer 122: 1505-1512, 2016.

56. Hoppe BS, Michalski JM, Mendenhall NP, Morris CG, Henderson RH, Nichols RC, Mendenhall WM, Williams CR, Regan MM, Chipman JJ, et al: Comparative effectiveness study of patient-reported outcomes after proton therapy or intensitymodulated radiotherapy for prostate cancer. Cancer 120 $1076-1082,2014$
57. Sheets NC, Goldin GH, Meyer AM, Wu Y, Chang Y, Stürmer T, Holmes JA, Reeve BB, Godley PA, Carpenter WR and Chen RC: Intensity-modulated radiation therapy, proton therapy, or conformal radiation therapy and morbidity and disease control in localized prostate cancer. JAMA 307: 1611-1620, 2012.

58. Hospital MG, Pennsylvania Uo, (NCI) NCI, et al: Proton therapy vs. IMRT for low or intermediate risk prostate cancer (PARTIQoL). https://clinicaltrials.gov/ct2/show/NCT01617161. Accessed June 12, 2012

59. Zaorsky NG, Harrison AS, Trabulsi EJ, Gomella LG, Showalter TN, Hurwitz MD, Dicker AP and Den RB: Evolution of advanced technologies in prostate cancer radiotherapy. Nat Rev Urol 10: 565-579, 2013.

60. Pugh TJ and Lee AK: Proton beam therapy for the treatment of prostate cancer. Cancer J 20: 415-420, 2014.

61. Johnstone PA, McMullen KP, Buchsbaum JC, Douglas JG and Helft P: Pediatric CSI: Are protons the only ethical approach? Int J Radiat Oncol Biol Phys 87: 228-230, 2013.

62. Sethi RV, Shih HA, Yeap BY, Mouw KW, Petersen R, Kim DY, Munzenrider JE, Grabowski E, Rodriguez-Galindo C, Yock TI, et al: Second nonocular tumors among survivors of retinoblastoma treated with contemporary photon and proton radiotherapy. Cancer 120: 126-133, 2014.

63. Taddei PJ, Mirkovic D, Fontenot JD, Giebeler A, Zheng Y, Kornguth D, Mohan R and Newhauser WD: Stray radiation dose and second cancer risk for a pediatric patient receiving craniospinal irradiation with proton beams. Phys Med Biol 54: 2259-2275, 2009

64. Merchant TE, Kiehna EN, Li C, Shukla H, Sengupta S, Xiong X, Gajjar A and Mulhern RK: Modeling radiation dosimetry to predict cognitive outcomes in pediatric patients with CNS embryonal tumors including medulloblastoma. Int $\mathbf{J}$ Radiat Oncol Biol Phys 65: 210-221, 2006.

65. Miralbell R, Lomax A, Cella L and Schneider U: Potential reduction of the incidence of radiation-induced second cancers by using proton beams in the treatment of pediatric tumors. Int J Radiat Oncol Biol Phys 54: 824-829, 2002.

66. Athar BS and Paganetti H: Comparison of second cancer risk due to out-of-field doses from 6-MV IMRT and proton therapy based on 6 pediatric patient treatment plans. Radiother Oncol 98: 87-92, 2011 .

67. Lee CT, Bilton SD, Famiglietti RM, Riley BA, Mahajan A, Chang EL, Maor MH, Woo SY, Cox JD and Smith AR: Treatment planning with protons for pediatric retinoblastoma, medulloblastoma, and pelvic sarcoma: How do protons compare with other conformal techniques? Int J Radiat Oncol Biol Phys 63: 362-372, 2005

68. Yock T, Schneider R, Friedmann A, Adams J, Fullerton B and Tarbell N: Proton radiotherapy for orbital rhabdomyosarcoma: Clinical outcome and a dosimetric comparison with photons. Int J Radiat Oncol Biol Phys 63: 1161-1168, 2005.

69. Mu X, Björk-Eriksson T, Nill S, Oelfke U, Johansson KA, Gagliardi G, Gagliardi G, Johansson L, Karlsson M and Zackrisson DB: Does electron and proton therapy reduce the risk of radiation induced cancer after spinal irradiation for childhood medulloblastoma? A comparative treatment planning study. Acta Oncol 44: 554-562, 2005.

70. Heidenreich PA, Schnittger I, Strauss HW, Vagelos RH, Lee BK, Mariscal CS, Tate DJ, Horning SJ, Hoppe RT and Hancock SL: Screening for coronary artery disease after mediastinal irradiation for Hodgkin's disease. J Clin Oncol 25: 43-49, 2007.

71. Hull MC, Morris CG, Pepine CJ and Mendenhall NP: Valvular dysfunction and carotid, subclavian, and coronary artery disease in survivors of hodgkin lymphoma treated with radiation therapy. JAMA 290: 2831-2837, 2003

72. Foote RL, Stafford SL, Petersen IA, Pulido JS, Clarke MJ, Schild SE, Garces YI, Olivier KR, Miller RC, Haddock MG, et al: The clinical case for proton beam therapy. Radiat Oncol 7: 174, 2012.

73. Sejpal S, Komaki R, Tsao A, Chang JY, Liao Z, Wei X, Allen PK, $\mathrm{Lu}$ C, Gillin M and Cox JD: Early findings on toxicity of proton beam therapy with concurrent chemotherapy for nonsmall cell lung cancer. Cancer 117: 3004-3013, 2011.

74. Plastaras JP, Berman AT and Freedman GM: Special cases for proton beam radiotherapy: Re-irradiation, lymphoma, and breast cancer. Semin Oncol 41, 807-819, 2014. 